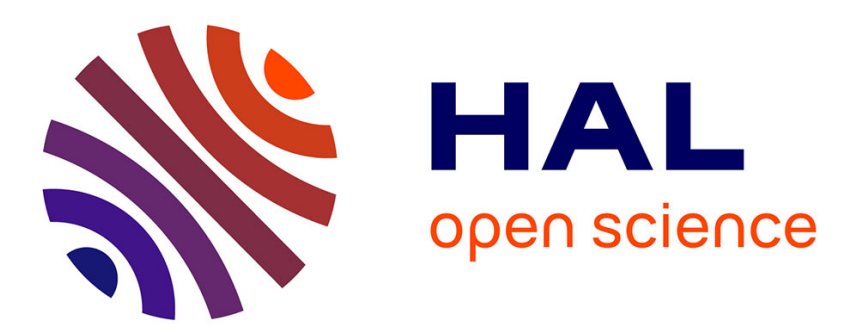

\title{
Errata - X-ray reflectivity of a Langmuir monolayer on water
}

\author{
Louis Bosio, J.J. Benattar, F. Rieutord
}

\section{To cite this version:}

Louis Bosio, J.J. Benattar, F. Rieutord. Errata - X-ray reflectivity of a Langmuir monolayer on water. Revue de Physique Appliquée, 1987, 22 (11), pp.1599-1599. 10.1051/rphysap:0198700220110159902 . jpa-00245715

\section{HAL Id: jpa-00245715 https://hal.science/jpa-00245715}

Submitted on 1 Jan 1987

HAL is a multi-disciplinary open access archive for the deposit and dissemination of scientific research documents, whether they are published or not. The documents may come from teaching and research institutions in France or abroad, or from public or private research centers.
L'archive ouverte pluridisciplinaire HAL, est destinée au dépôt et à la diffusion de documents scientifiques de niveau recherche, publiés ou non, émanant des établissements d'enseignement et de recherche français ou étrangers, des laboratoires publics ou privés. 


\section{Errata}

X-ray reflectivity of a Langmuir monolayer on water

de L. Bosio, J. J. Benattar and F. Rieutord

paru dans la section Instrumentation du numéro d'août 87 ; étaient des NOTES BRÈVES. 